\title{
Influence of WC and Co in Cutting Cemented Carbides with PCD and CBN Tools
}

\author{
Takeshi Miyamoto ${ }^{1, a}$, Junsuke Fujiwara ${ }^{2, b}$ and Keisuke Wakao ${ }^{3, c}$ \\ ${ }^{1}$ Kobe City College of Technology, Kobe, 651-2194, Japan \\ ${ }^{2}$ Osaka University, Suita, 565-0871, Japan \\ ${ }^{3}$ Osaka University, Suita, 565-0871, Japan \\ amiyamoto@kobe-kosen.ac.jp, ${ }^{b}$ fujiwara@mech.eng.osaka-u.ac.jp, \\ cwakao@mapro.mech.eng.osaka-u.ac.jp
}

Keywords: Cutting, Cemented carbides, Tool wear mechanism, PCD, cBN

\begin{abstract}
In this study, turning of the cemented carbides that their WC particle size was standardized were carried out with the PCD and the cBN tools. The WC particle diameter of cemented carbides was about $2 \mu \mathrm{m}$ and the Co contents were 10, 15, 20 and 25\%, respectively. The influence of the WC particle size and Co contents was investigated. Summary of results are shown as follows: (1) In turning with the PCD tool, the more the Co contents increase, the more the tool wear increases. (2) In turning with the cBN tools, the more the Co contents of the work material increase, the more the tool wear decreases. (3) In turning of the cemented carbides contained the larger quantity of $\mathrm{Co}$, the $\mathrm{cBN}$ tools are more effective than the PCD tool.
\end{abstract}

\section{Introduction}

Cemented carbides have high hardness, and they are used for not only cutting tools but also dies. Commonly, the grinding of their products is used for finish machining. On the other hand, the cutting is sometimes used in the efficient processing. However, it is well known that cemented carbides are difficult-to-cut materials and the tool wear is very severe in cutting with the PCD tool [1]-[5]. It is necessary to make clear the machinability in cutting the cemented carbides in detail. In previous study, the tool life was compared among four kinds of cemented carbides. The turning [6], the micro cutting in the SEM [7] and the mist and wet turning [8] were carried out to make clear the tool wear mechanism. As these work materials were not standardized the WC particle size and Co contents, the relationship between tool life and the WC particle size, Co contents could not be made clear. Then in this study, the turning of the cemented carbides that the WC particle diameter was standardized was carried out. The Co contents were 10, 15, 20 and 25\%, respectively. The tool wear was measured and the worn flank was observed.

\section{Experimental Method}

Work Materials. The work materials are four cemented carbides. Their structures are shown in Figure 1. The diameter of WC particle contained in them is standardized and is about $2 \mu \mathrm{m}$. The Co contents are 10, 15, 20 and 25\%, respectively. Their mechanical properties are shown in Table 1. As the Co contents increase, both the hardness and the compressive strength decrease.
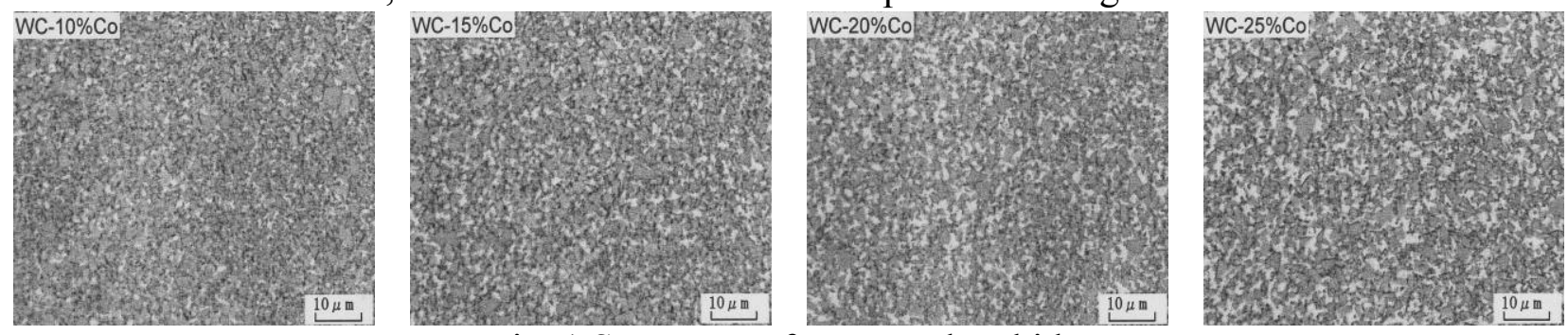

Fig. 1 Structures of cemented carbides 
Table 1 Mechanical properties of cemented carbides

\begin{tabular}{c|c|c|c}
\hline $\begin{array}{c}\text { Cemented } \\
\text { carbide }\end{array}$ & $\begin{array}{c}\text { Density } \\
{\left[\mathrm{Mg} / \mathrm{m}^{3}\right]}\end{array}$ & $\begin{array}{c}\text { Hardness } \\
{[\mathrm{HV}]}\end{array}$ & $\begin{array}{c}\text { Compressive } \\
\text { strength } \\
{[\mathrm{GPa}]}\end{array}$ \\
\hline $\mathrm{WC}-10 \% \mathrm{Co}$ & 14.55 & 946 & 3.570 \\
\hline $\mathrm{WC}-15 \% \mathrm{Co}$ & 14.05 & 924 & 3.535 \\
\hline $\mathrm{WC}-20 \% \mathrm{Co}$ & 13.60 & 904 & 3.485 \\
\hline $\mathrm{WC}-25 \% \mathrm{Co}$ & 13.15 & 885 & 3.237 \\
\hline
\end{tabular}

Tool Materials. The PCD(Poly Crystalline Diamond) and three kinds of cBN(cubic Boron Nitride) tools were used. Their mechanical properties are shown in Table 2. The hardness and transverse rupture strength of the PCD tool is the highest among them. The symbols of three cBN tools are $\mathrm{cBN}-1, \mathrm{cBN}-2$ and $\mathrm{cBN}-3$, respectively. The grain contents of $\mathrm{cBN}-1$ and $\mathrm{cBN}-2$ are $50-60$ volume $\%$, and one of $\mathrm{cBN}-3$ is $80-90$ volume $\%$. The grain size of three cBN tools is similar. The bonding material of $\mathrm{cBN}-1$ and $\mathrm{cBN}-2$ is TiN, and one of $\mathrm{cBN}-3$ is $\mathrm{Co}$.

Table 2 Mechanical properties of tool materials

\begin{tabular}{c|c|c|c|c|c}
\hline Tool & $\begin{array}{c}\text { Grain contents } \\
{[\mathrm{Vol} \%]}\end{array}$ & $\begin{array}{c}\text { Grain size } \\
{[\mu \mathrm{m}]}\end{array}$ & $\begin{array}{c}\text { Bonding } \\
\text { material }\end{array}$ & $\begin{array}{c}\text { Hardness } \\
{[\mathrm{HV}]}\end{array}$ & $\begin{array}{c}\text { Transverse } \\
\text { rupture strength } \\
{[\mathrm{GPa}]}\end{array}$ \\
\hline PCD & 91 & 12.5 & $\mathrm{Co}$ & 10000 & 1.70 \\
\hline $\mathrm{cBN}-1$ & $50-60$ & 2 & TiN & $3200-3400$ & $1.00-1.10$ \\
\hline $\mathrm{cBN}-2$ & $50-60$ & 3 & TiN & $3200-3400$ & $0.95-1.10$ \\
\hline $\mathrm{cBN}-3$ & $80-90$ & 3 & Co & $3900-4200$ & $0.95-1.10$ \\
\hline
\end{tabular}

Cutting Experiment. The turning test was carried out with the $\mathrm{CNC}$ lathe. The cutting conditions are shown in Table 3. The cutting speed is different in case of the PCD and cBN tools. The feed rate is $0.1 \mathrm{~mm}$ and the depth of cut is $0.1 \mathrm{~mm}$. When flank wear width became more than $0.3 \mathrm{~mm}$, the cutting test was stopped.

Table 3 Cutting conditions

\begin{tabular}{c|c|c}
\hline Cutting tools & PCD & cBN-1, cBN-2, cBN-3 \\
\hline Cutting speed V $[\mathrm{m} / \mathrm{min}]$ & 15 & 10 \\
\hline Feed rate $\mathrm{f}[\mathrm{mm} / \mathrm{rev}]$ & 0.1 \\
\hline Depth of cut $\mathrm{t}[\mathrm{mm}]$ & 0.1 \\
\hline Tool configuration & \multicolumn{2}{|c}{$(-5,-5,5,5,30,0,0.8)$} \\
\hline Cutting method & Dry
\end{tabular}

\section{Results and Discussion}

Tool Wear and Chip in PCD Tool. Figure 2 shows the relation between the flank wear width and the cutting distance when all work materials are turned with the PCD tool. The more the Co contents increase, the more the tool wear increases. It is clear that the Co contents affect on the flank wear in cutting the cemented carbide of WC particle diameter $2 \mu \mathrm{m}$. Figure 3 is the optical micro photograph of the flank face and the rake face at when the flank wear width becomes $0.3 \mathrm{~mm}$. The symbol of $\mathrm{L}$ is a cutting distance. The face wear of all work materials is little. Figure 4 is the SEM photograph of the flank face at when the flank wear width becomes $0.3 \mathrm{~mm}$. The adhesion on the flank face seems to be the largest in turning WC-10\%Co. Figure 5 is the optical micro photograph of chips. The chip configuration in $\mathrm{WC}-25 \% \mathrm{Co}$ is a continuous type and one in $\mathrm{WC}-10 \% \mathrm{Co}$ is a segmented type and small. 

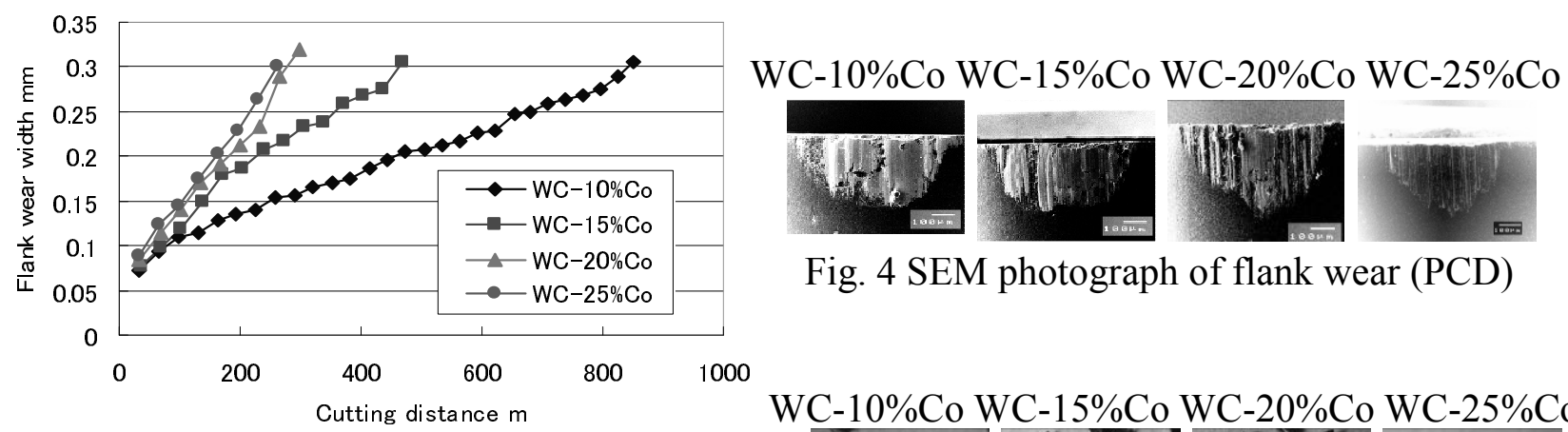

Fig. 4 SEM photograph of flank wear (PCD)

Fig. 2 Relation between flank wear width and cutting distance (PCD)

WC-10\%Co WC-15\%Co WC-20\%Co WC-25\%Co
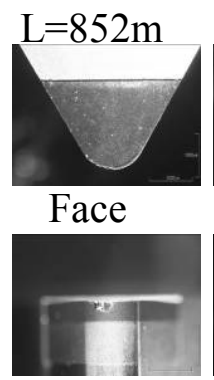

Flank

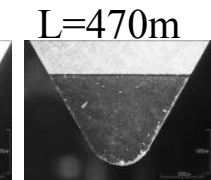

Face

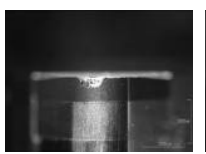

Flank

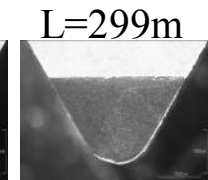

Face

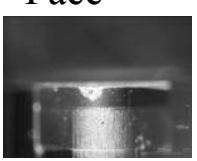

Flank

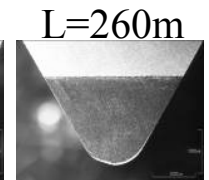

Face

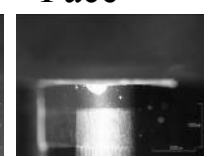

Flank $1 \mathrm{~mm}$

WC- $10 \%$ Co WC- $15 \%$ Co WC- $20 \%$ Co WC- $25 \%$ Co
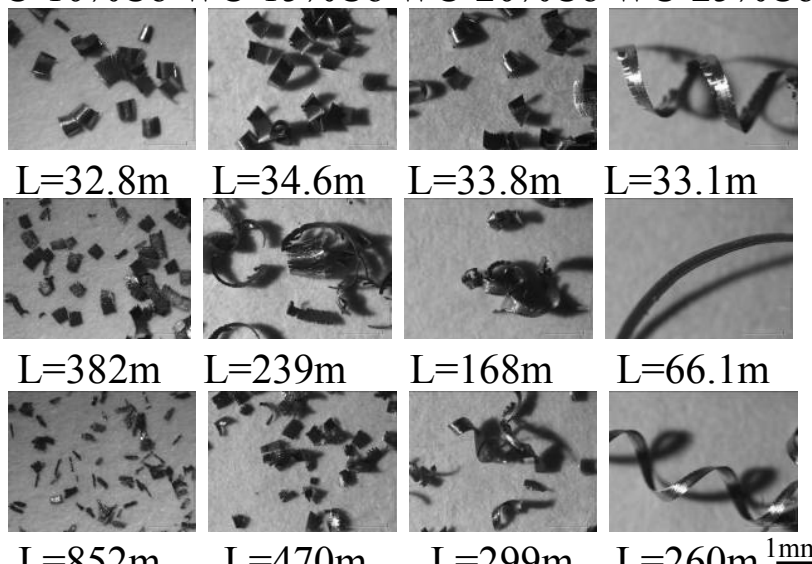

$\mathrm{L}=239 \mathrm{~m}$

$\mathrm{L}=168 \mathrm{~m}$ $\mathrm{L}=66.1 \mathrm{~m}$

Fig. 3 Optical micro-photographs of PCD

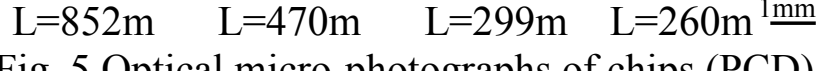

Tool Wear and Chip in $\mathbf{c B N}-3$ Tool. Figure 6 shows the relation between the flank wear width and the cutting distance with $\mathrm{cBN}-3$ tool. In contrast to the PCD, as the Co contents increase, the tool wear decreases. The wear progress of the $\mathrm{cBN}-1$ and the $\mathrm{cBN}-2$ were similar to that of the $\mathrm{cBN}-3$. Figure 7 is the optical micro photograph of the flank face and the rake face at when the flank wear width becomes $0.3 \mathrm{~mm}$. Figure 8 is the SEM photograph of the flank face at when the flank wear width becomes $0.3 \mathrm{~mm}$. The adhesion seems to be small. Figure 9 is the optical micro photograph of chips. The chip configuration is a segmented type.

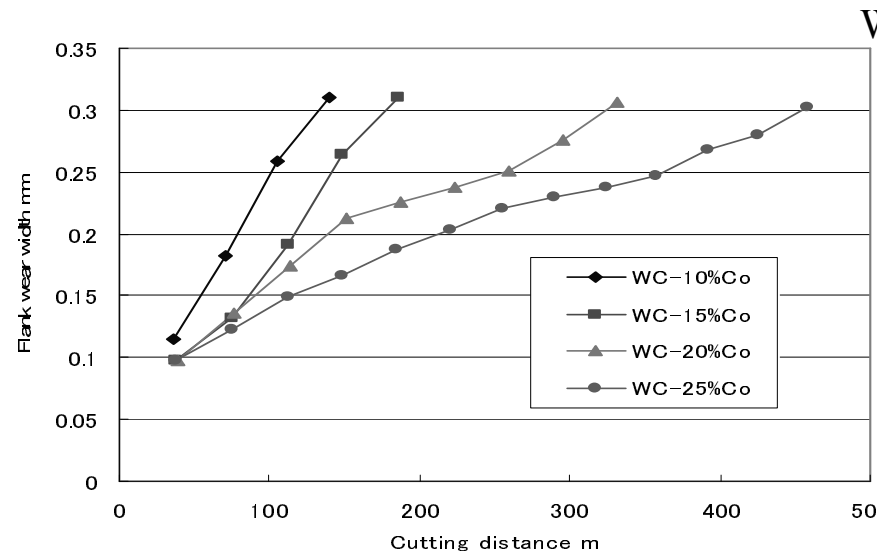

WC-10\%Co WC- $15 \%$ Co WC- $20 \%$ Co WC- $25 \%$ Co

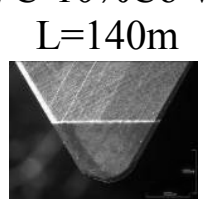

Face

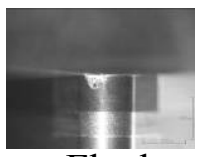

Flank

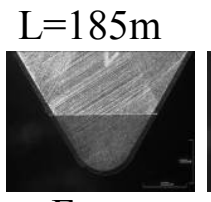

Face

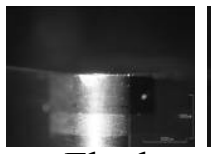

Flank

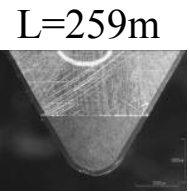

Face

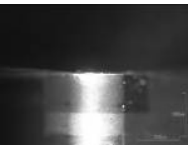

Flank

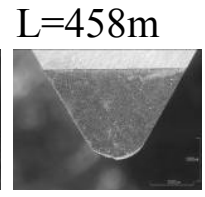

Face

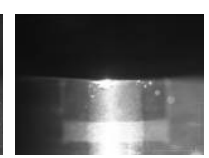

Flank $1 \underline{\mathrm{mm}}$

Fig. 7 Optical micro-photographs of cBN-3

Fig. 6 Relation between flank wear width WC-10\%Co WC-15\%Co WC-20\%Co WC-25\%Co and cutting distance $(\mathrm{cBN}-3)$
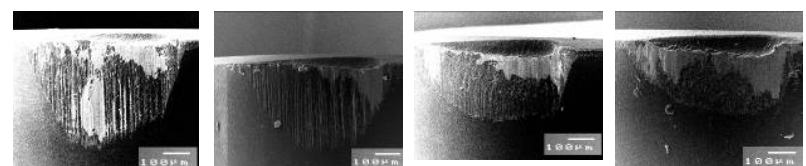

Fig. 8 SEM photograph of flank wear $(\mathrm{cBN}-3)$ 
Figure 10 shows the relation between the flank wear width and the cutting distance in cutting WC-25\%Co with different cBN tools. The flank wear of the cBN-3 is the smallest and one of the cBN-1 is the largest. As shown in Table 2, it is clear that the grain contents and the bonding materials effect on the flank wear width. As compared Fig.2 with Fig.6, the flank wear width of $\mathrm{cBN}-3$ is smaller than one of PCD in cutting WC- $20 \% \mathrm{Co}$ and WC- $25 \%$ Co.

\section{Conclusions}

The main results obtained are as follows:

(1) In turning with the PCD tool, the more the Co contents increase, the more the tool wear increases.

(2) In turning with the cBN tools, the more the Co contents of the work material increase, the more the tool wear decreases.

(3) In turning of the cemented carbides contained the larger quantity of $\mathrm{Co}$, the $\mathrm{cBN}$ tools are more effective

WC-10\%Co WC-15\%Co WC-20\%Co WC- $25 \%$ Co
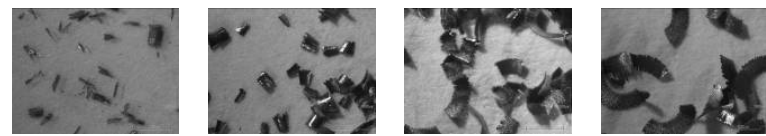

$\mathrm{L}=35.6 \mathrm{~m}$

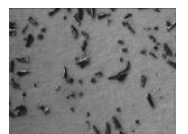

$\mathrm{L}=140 \mathrm{~m}$

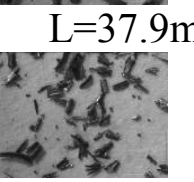

$\mathrm{L}=185 \mathrm{~m}$

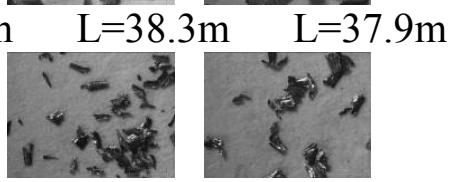

$\mathrm{L}=259 \mathrm{~m} \quad \mathrm{~L}=458 \mathrm{~m}$ Fig. 9 Optical micro-photographs of chips (cBN-3)

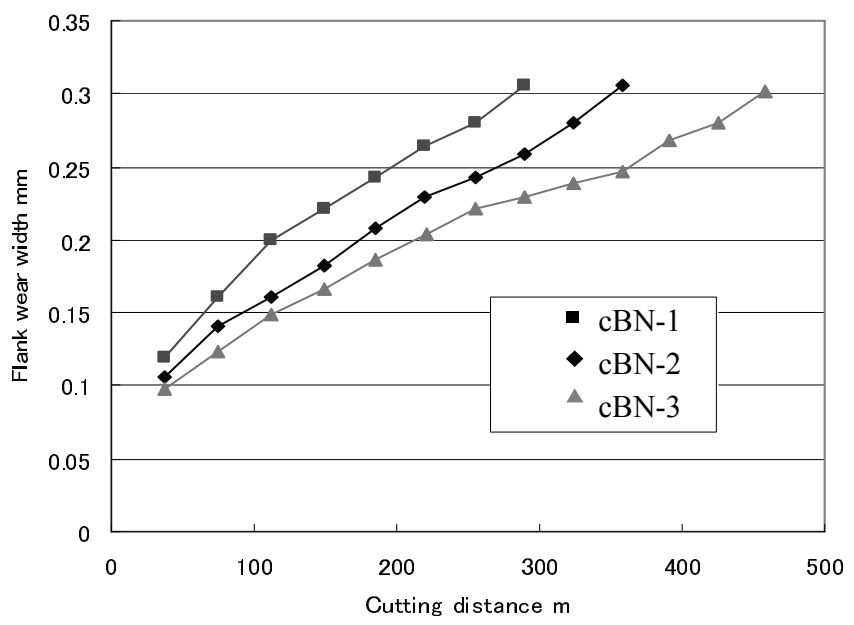

Fig. 10 Relation between flank wear width and cutting distance (WC-25\%Co) than the PCD tool.

\section{References}

[1] Japan Society for the Promotion of Machine Industry, Cutting Data Files (Technical Research Institute, Tokyo, Japan 1988, 86-097) (in Japanese)

[2] Japan Society for the Promotion of Machine Industry, Cutting Data Files, (Technical Research Institute, Tokyo, Japan 1995, 92-0298) (in Japanese)

[3] Japan Society for the Promotion of Machine Industry, Cutting Data Files, (Technical Research Institute, Tokyo, Japan 1997, 95-0321) (in Japanese)

[4] Japan Society for the Promotion of Machine Industry, Cutting Data Files, (Technical Research Institute, Tokyo, Japan 1997, 95-0323) (in Japanese)

[5] Japan Society for the Promotion of Machine Industry, Cutting Data Files, (Technical Research Institute, Tokyo, Japan 1997, 95-0325) (in Japanese)

[6] S. J. Heo, T. Miyamoto, S. Hanasaki, J. Fujiwara: J. of the Japan Society for Precision Engineering, Vol.69, No.12 (2003), p.1724-1728 (in Japanese)

[7] S. J. Heo, T. Miyamoto, J. Fujiwara, S. Hanasaki: Proc. of the Sixth International Conference on Progress of Cutting Technology (2002), p.218-223

[8] S. J. Heo, T. Miyamoto, J. Fujiwara, S. Hanasaki, S. Amano: J. of the Japan Society for Precision Engineering, Vol.73, No.8 (2007), p.896-900 (in Japanese) 